\title{
Chronic postsurgical pain in mixed surgical population. Does an acute pain service make a difference?
}

\author{
Kubricht $\mathrm{V}^{1,2}$, Sevcik $\mathrm{P}^{2,3,4}$ \\ Department of Anesthesiology and Intensive Care, Pribram District Hospital, Czech Republic and Faculty \\ of Medicine, Masaryk University Brno, Brno, Czech Republic. viktor.kubricht@gmail.com
}

\begin{abstract}
OBJECTIVES: To investigate the influence of an Acute Pain Service (APS) on the incidence of chronic postsurgical pain (CPSP). To assess the acute pain intensity as a risk factor for CPSP. The impact of an APS on the incidence of CPSP has not yet been studied.

METHODS: Retrospective questionnaire given to randomized cohorts study, performed in two hospitals - Hospital A with an APS and Hospital B without such service. 1444 patients underwent eight different surgical procedures in both hospitals within one year, 175 patients from each hospital were randomized.

RESULTS: 208 questionnaires were analysed. There was a significant difference in acute pain intensity in the first 24 hours after surgery. The difference of CPSP incidence between hospitals was not significant (Hospital A nine patients $(8.6 \%)$, Hospital B sixteen patients (15.5\%). The patients with CPSP experienced significantly more intensive pain in the first 24 hours and at discharge than patients without CPSP regardless of the hospital. CONCLUSION: The study did not demonstrate the incidence of CPSP was lower in the hospital with an APS despite the lower postoperative pain scores. However there was a noticeable trend toward higher incidence of CPSP in the hospital without an APS. The study demonstrated that APS decreases intensity of an acute postoperative pain and acute pain intensity is a risk factor for CPSP incidence (Tab. 5, Ref. 27). Text in PDF www.elis.sk. KEY WORDS: chronic postsurgical pain, acute pain service, questionnaire.
\end{abstract}

\section{Introduction}

CPSP is a well-recognized complication of surgical care. Its prevalence varies and is estimated to be between $5-85 \%$ in a population of surgical patients undergoing different types of procedures (1-4). The prevalence of CPSP varies very significantly according to the type of operation (5-14). Risk factors include preoperative, perioperative and postoperative conditions, and the type and technique of the procedure itself. Among the most important factors are age, gender, pain before the operation, level of anxiety or catastrophizing before the operation, type of operation, operative technique, and the intensity and duration of acute pain $(1,3,4,6,8-11,14-16)$.

To improve acute pain management, decrease prevalence and intensity of acute postoperative pain, and to decrease the incidence of postoperative complications, many hospitals have developed an APS. APSs have been shown to decrease the intensity of acute postoperative pain (17-20). In our study, we have attempted to

Department of Anesthesiology and Intensive Care, Pribram District Hospital, Czech Republic, ${ }^{2}$ Faculty of Medicine, Masaryk University Brno, Brno, Czech Republic, ${ }^{3}$ Department of Intensive Care Medicine and Forensic Studies, Faculty of Medicine, University of Ostrava, Czech Republic, and ${ }^{4}$ Department of Anesthesiology and Intensive Care, Faculty of Medicine, University Hospital Ostrava, Ostrava, Czech Republic

Address for correspondence: V. Kubricht, MD, Simackova 1378/2, CZ17000 Prague 7, Czech Republic.

Phone: +420605234502 determine whether the presence of an established APS alters the incidence of CPSP and whether patients with stronger acute pain suffer more often from CPSP.

\section{Patients and methods}

We performed a randomized retrospective cohort questionnaire study. The study was approved by the Ethical Board of Pribram District Hospital.

\section{Study settings}

The study took place in two mid-sized urban-based general hospitals (Hospital A and Hospital B). In Hospital A, there has been an established nurse-based anaesthesiologist-supervised APS and acute pain incidence and intensity as well as postoperative complications were regularly audited. These audits have demonstrated a reduction in the intensity of acute postoperative pain following the introduction of the APS. In Hospital B, there was no established APS; acute pain management was provided by ward staff according to local guidelines and customs. The numerical rating scale (NRS) was used to monitor pain intensity in both hospitals. Patients in the both hospitals were routinely given education on the NRS prior to their operation. All patients from both hospitals received multimodal analgesia with paracetamol, metamizol or a nonsteroidal antiinflammatory drug (NSAID) and opioids. Bupivacaine or levobupivacaine was used if the patient received a regional analgesic technique. 


\section{CPSP definition}

CPSP was defined by the criteria proposed by Macrae (21) and modified by the duration of pain in accordance with the original definition of Merskey et al (22) and later by Kehlet (23): 1) pain developed after a surgical procedure, 2) other causes for the pain had been excluded, 3) postsurgical pain was not a continuation of preoperative pain, 4) the pain was of at least 3 months duration. This time definition has been recently suggested by International Association for the Study of Pain (IASP) and the World Health Organization (WHO) Task force for classification of chronic pain for the new definition of CPSP in International Classification of Diseases (ICD) (24).

\section{Selection of patients}

We identified all surgical procedures performed by the Departments of General Surgery, Orthopedics, Gynecology and Urology in 2012 in both hospitals. There were 4,763 such procedures recorded in Hospital A and 5,105 in Hospital B. Patients, who underwent the following surgical procedures, were identified from the databases of both hospitals: laparotomy for bowel surgery, radical mastectomy with axillary exenteration, inguinal hernia repair, open nephrectomy, open radical prostatectomy, elective hip arthroplasty, elective knee arthroplasty and laparoscopic assisted vaginal hysterectomy (LAVH). These surgeries were selected because they were performed in both hospitals in significant numbers, they usually had similar postoperative courses, and most are known for a higher incidence of CPSP. There were 765 patients in Hospital A and 679 patients in Hospital B, who underwent one of the selected procedures.

From these patients we randomly selected 175 patients in each hospital. This resulted in 350 patients for analysis: 175 patients from each hospital, grouped into eight procedures with equal numbers from Hospital 1 and Hospital 2 for each procedure (Tab. 1).

Exclusion criteria were age less than 18 years, death during the period between procedure and research, chronic pain (longer than 3 months) at the site of surgery prior to operation, reoperation or new operation at the site of original operation in the period between original procedure and research, recorded postoperative complications with wound healing, or recorded cognitive disorder during the patient's stay in hospital.
We did not perform a prospective power analysis for this study due to the broad range of published incidence of CPSP following different surgical procedures $(1,2,3,4)$ and the lack of studies looking at the influence of an APS on CPSP and of studies, which would estimate the level of importance of acute pain intensity changes on CPSP incidence. It was therefore not possible to reasonably estimate the anticipated incidence of CPSP in each group.

\section{Data collection}

For each patient, we recorded the patient age, gender, and type of anaesthesia (general, regional or combined general-regional).

Each selected patient received a questionnaire to assess the patient's experience with pain and pain management during his or her stay in the hospital and then in the months after the procedure. The questionnaire's intelligibility, comprehensiveness and the time needed to complete it were tested in 5 patients who were not included in the study. The questionnaire with a letter of explanation about the study was sent during June 2013 (6-18 months after the operations). Non-responding patients were called by telephone and asked to participate in the study. In the first round we received 186 completed questionnaires and after the telephone reminder additional 43 completed questionnaires were obtained. The original questionnaire is in the Czech language, its translation into English is in Appendix 1: Patient questionnaire. NRS of 0 to 10 was used for pain intensity assessment.

\section{Statistical analysis}

From the received responses we determined the following variables: pain in the first 24 hours, pain at the time of discharge from the hospital and pain after discharge from hospital (at 1 month, 2 months, 3 months and more than 3 months).

We determined 1) if the patients from each hospital were comparable in terms of surgical procedures and age, gender and type of anaesthesia; 2) any difference in pain intensity during the first 24 hours after surgery and at discharge from the hospital; 3) presence of pain at the month 1 , month 2 , month 3 or later than 3 months. Patients with CPSP ( 3 months or longer) from both hospitals were compared in terms of intensity of pain during the first 24 hours after surgery and at discharge from the hospital to establish any possible connection between acute pain intensity and

Tab. 1. Number of randomized patients and number of the questionnaire responders in total and by the procedure.

\begin{tabular}{|c|c|c|c|c|}
\hline & \multicolumn{2}{|c|}{ Hospital A } & \multicolumn{2}{|c|}{ Hospital B } \\
\hline & $\begin{array}{l}\text { Number of sent } \\
\text { questionnaires }\end{array}$ & $\begin{array}{c}\text { Eligible for analysis } \\
\text { (\% of all sent } \\
\text { questionnaires) }\end{array}$ & $\begin{array}{l}\text { Number of sent } \\
\text { questionnaires }\end{array}$ & $\begin{array}{c}\text { Eligible for analysis } \\
\text { (\% of all sent } \\
\text { questionnaires) }\end{array}$ \\
\hline Total & 175 & $105(60 \%)$ & 175 & $103(59 \%)$ \\
\hline Laparotomy for bowel surgery & 35 & 20 & 35 & 20 \\
\hline Radical mastectomy with axillary exenteration & 10 & 6 & 10 & 7 \\
\hline Inguinal hernia repair & 35 & 22 & 35 & 23 \\
\hline Open radical prostatectomy & 12 & 6 & 12 & 6 \\
\hline Open nephrectomy & 13 & 7 & 13 & 6 \\
\hline Hip arthroplasty & 22 & 11 & 22 & 12 \\
\hline Knee arthroplasty & 20 & 11 & 20 & 12 \\
\hline LAVH1) & 28 & 22 & 28 & 17 \\
\hline
\end{tabular}

${ }^{1)}$ Laparoscopic assisted vaginal hysterectomy 
the incidence of CPSP. Main outcomes were: acute pain intensity, CPSP incidence, and associations of CPSP incidence and acute pain intensity to presence or absence of APS. The level of significance was set as $\mathrm{p}<0.05$. The Fisher exact test was used for categorical variables and the Mann-Whitney U test was used for continuous variables. For statistical analysis we used the statistical software package SPSS 22.0.0.1 (IBM Corporation).

\section{Results}

We received 229 questionnaires from the 350 originally sent and we excluded all patients, who had pain for more than 3 months at the site of surgery prior to operation (21 patients). This left 208 questionnaires (105 and 103 from each hospital) to analyse (Tab. 1).

There was no significant difference in age or gender or type of anaesthesia between two groups of patients from different hospi- tals in total or in any subgroup of surgical procedures (Tab. 2). 94 of 105 patients of Hospital A and 86 of 104 patients of Hospital B remembered their pain in the first 24 hours after surgery. Pain at discharge remembered 102 patients of Hospital A and 99 patients of Hospital B. There was a significant difference between the two groups of patients in the level of pain experienced in the first 24 hours after surgery. Patients from Hospital A (with an established APS) experienced a significantly lower intensity of pain. There was no significant difference in pain intensity experienced at discharge from the hospitals (Tab. 3).

Data about the incidence of CPSP have showed that nine (8.6\%) patients from Hospital A and sixteen (15.5\%) patients from Hospital B experienced CPSP. However, this difference was not statistically significant (Tab. 4).

Measurements of the difference in in acute pain intensity between the patients with CPSP and without CPSP have showed

Tab. 2. Demographic data and type of anaesthesia.

\begin{tabular}{|c|c|c|c|c|}
\hline & & $\begin{array}{c}\text { Hospital A }(\mathrm{n}=105) \\
\mathrm{n}(\%) \text { or median }(\min -\max )\end{array}$ & $\begin{array}{c}\text { Hospital B }(\mathrm{n}=103) \\
\mathrm{n}(\%) \text { or median }(\min -\max )\end{array}$ & $\mathrm{p}^{1)}$ \\
\hline Age & & $69(38-86)$ & $67(44-84)$ & 0.445 \\
\hline Gender & $\begin{array}{l}\text { Men } \\
\text { Women }\end{array}$ & $\begin{array}{l}46(44 \%) \\
59(56 \%)\end{array}$ & $\begin{array}{l}52(50 \%) \\
51(50 \%)\end{array}$ & 0.405 \\
\hline Type of anesthesia & $\begin{array}{l}\text { General } \\
\text { Combined } \\
\text { Regional }\end{array}$ & $\begin{array}{l}61(58 \%) \\
20(19 \%) \\
24(23 \%)\end{array}$ & $\begin{array}{l}50(49 \%) \\
26(25 \%) \\
27(26 \%)\end{array}$ & 0.356 \\
\hline
\end{tabular}

Tab. 3. Acute pain intensity in the first 24 hours and at discharge for whole population of patients (NRS 0 to 10)

\begin{tabular}{lccc}
\hline & Hospital A & Hospital B & $\mathrm{p}^{1)}$ \\
\hline $\begin{array}{l}\text { Pain in the first 24 hours } \\
\text { Median (min-max)/Mean }\left(\mathrm{SD}^{2)}\right)\end{array}$ & $3(0-10) / 3.4(2.0)$ & $4(0-10) / 4.2(2.3)$ & 0.05 \\
\hline $\begin{array}{l}\text { Pain at discharge } \\
\text { Median (min-max)/Mean (SD) }\end{array}$ & $2(0-10) / 1.9(1.6)$ & $2(0-8) / 2.2(1.7)$ & 0.236 \\
\hline
\end{tabular}

${ }^{1)} \mathrm{p}$ value of Mann-Whitney $\mathrm{U}$ test for continuous variables ${ }^{2)}$ Standard deviation

Tab. 4. Duration of pain and CPSP incidence.

\begin{tabular}{|c|c|c|c|c|}
\hline & & $\begin{array}{l}\text { Hospital A (105 patients) } \\
\text { Number of patients }(\%)\end{array}$ & $\begin{array}{l}\text { Hospital B (103 patients) } \\
\text { Number of patients ( } \%)\end{array}$ & $\mathrm{p}^{1)}$ \\
\hline $\mathrm{CPSP}^{2)}$ (3 month and longer) & & $9(8.6 \%)$ & $16(15.5 \%)$ & 0.139 \\
\hline \multirow{4}{*}{ Duration of pain } & Patient does not know & $5(4.8 \%)$ & $10(9.7 \%)$ & 0.313 \\
\hline & $<1$ month & $59(56.2 \%)$ & $49(47.6 \%)$ & \\
\hline & $1-2$ month & $32(30.5 \%)$ & $28(27.2 \%)$ & \\
\hline & $\geq 3$ month & $9(8.6 \%)$ & $16(15.5 \%)$ & \\
\hline
\end{tabular}

Tab. 5. Acute pain intensity in the first 24 hours and at discharge. Patients with CPSP vs. patients without CPSP (NRS 0 to 10).

\begin{tabular}{|c|c|c|c|c|}
\hline Hospital A & & CPSP patients & Non-CPSP patients & $\mathrm{p}^{1)}$ \\
\hline Pain intensity in the first 24 hours & $\begin{array}{l}\text { Median }(\min -\max ) \\
\text { Mean }\left(\mathrm{SD}^{2)}\right)\end{array}$ & $\begin{array}{l}5(4-10) \\
6.6(2.17) \\
\end{array}$ & $\begin{array}{l}3(0-7) \\
3.1(1.7)\end{array}$ & $<0.05$ \\
\hline Pain intensity at discharge & $\begin{array}{l}\text { Median }(\min -\max ) \\
\text { Mean }\left(\mathrm{SD}^{2)}\right)\end{array}$ & $\begin{array}{c}3(4-10) \\
5.1(2.51)\end{array}$ & $\begin{array}{c}2(0-5) \\
1.7(1.35) \\
\end{array}$ & $<0.05$ \\
\hline Hospital 2 & & CPSP patients & Non-CPSP patients & $\mathrm{p}^{1)}$ \\
\hline Pain intensity in the first 24 hours & $\begin{array}{l}\text { Median (min-max) } \\
\text { Mean (SD) }\end{array}$ & $\begin{array}{c}8(5-10) \\
7.5(1.45) \\
\end{array}$ & $\begin{array}{c}3(0-8) \\
3.6(1.94) \\
\end{array}$ & $<0.05$ \\
\hline Pain intensity at discharge & $\begin{array}{l}\text { Median }(\min -\max ) \\
\text { Mean }(\mathrm{SD})\end{array}$ & $\begin{array}{c}5(1-8) \\
4.4(2.09)\end{array}$ & $\begin{array}{c}2(1-8) \\
1.8(1.27)\end{array}$ & $<0.05$ \\
\hline
\end{tabular}

${ }^{1)} \mathrm{p}$ value of Mann-Whitney U test for continuous variables ${ }^{2)}$ Standard deviation 
the patients with CPSP experienced significantly more intensive acute pain in the first 24 hours and at discharge in both hospitals. Acute pain intensity was a significant risk factor for CPSP development (Tab. 5).

As there was no significant difference in the incidence of CPSP between the groups of patients from the two hospitals, we did not analyse the intensity and frequency of this pain (Part $\mathrm{C}$ of the questionnaire).

\section{Discussion}

\section{Patients, methods and settings}

To the best of our knowledge, this is the first study to investigate possible role of an APS in prevention of CPSP. CPSP incidence varies significantly. Procedures chosen for our study have a significant estimated risk of CPSP development. The following incidences of CPSP have been reported: $18 \%$ following laparotomy for gastrointestinal surgery (5), up to $48 \%$ following radical mastectomy (6), up to $39 \%$ following hernia repair (7-9), $14 \%$ after radical prostatectomy (10), $28 \%$ after open nephrectomy (11), $44 \%$ after knee replacement (12) and up to $48 \%$ after total hip arthroplasty $(12,13)$. Althaus et al (15) found that the incidence of CPSP was $43.3 \%$ six months after surgery in a mixed surgical population.

Risk factors for CPSP are numerous and include age, gender, possible genetic predisposition, the patient's psychological condition prior to surgery (mood, expectation, catastrophizing, capacity overstrain), type of surgery and surgical technique, intensity of preoperative pain and intensity of postoperative pain. Althaus et al (15) showed that acute pain itself is an independent risk factor for CPSP. Acute pain as an important and strong risk factor of CPSP is stated in number of other studies $(1,2,4,6,8,11,14)$. There are many factors, which can determine experienced acute pain, and only some are alterable. Identification of such factors and best possible utilisation of all pain relieving and preventing measures is a key role of an APS. APS improves pain relieve of inpatients by better delivery of accessible pain management techniques and approaches. Many well defined interventions help to improve experienced acute pain (e.g. patient controlled analgesia (25), physiotherapy (26), implementation of guidelines and a quality management system (27) and many others). APS coordinates all these interventions and measures. The major reason for establishing an APS is to decrease the incidence and intensity of acute postoperative pain but it is possible that APS may also decrease the incidence of CPSP. The effectiveness of APSs in reducing acute pain intensity has been proved in numerous studies $(16,17,18,19$, 20). Sartain et al (18) showed that the introduction of APS reduced the incidence of severe acute postsurgical pain at rest nearly six times from $18.1 \%$ to $3.5 \%$, and pain with movement almost two times from $50 \%$ to $31 \%$. Bardiau et al (19) showed that the introduction of APS reduced the mean visual analogue scale (VAS) scores from 1.5 to 1.0, but maximal VAS scores were reduced from 4.8 to 3.9 and there was a significant reduction in the time patients spent in pain (12 hours with a VAS of 3 or more before introduction of an APS versus 6 hours following introduction of an APS).
The simple questionnaire was proven as a helpful tool in data collection in numerous retrospective studies on $\operatorname{CPSP}(7,13,14)$.

\section{Results}

The core premise that APS decreases the intensity of acute postoperative pain was confirmed. This study showed that the presence of APS was associated with a lower incidence of acute postoperative pain in a group of patients undergoing different types of surgical procedures. Patients from the hospital with an APS experienced a lower intensity of acute pain in the first 24 hours after operation. While it seems reasonable to think that a functioning APS might influence the severity or duration of CPSP we were not able to demonstrate this. There was a trend for fewer patients from the hospital with an APS to develop CPSP, but this was not statistically significant. Statistical power analysis based on the results of the study showed there would have to be 660 patients in each group to demonstrate a statistically significant difference in CPSP incidence. Sufficient power analysis prior to the study was not done because of very broad range of CPSP incidence published in different studies. CPSP incidence varies from 0 to $85 \%$ according to the type of surgery. We intentionally chose more different surgical procedures in to the study to demonstrate possible influence of the APS on surgical population in general, not only on the selected procedure. Perkins et al (4) involved in their study on CPSP incidence different studies with minimal number of involved patients, 25 to 100 , according to the anticipated incidence of CPSP for particular type of surgical procedure. We involved 175 patients in each group and performed power analysis after the study. The result of power analysis can help to estimate sufficient number of patients for further studies.

The study demonstrated one more important finding - patients (from both hospitals - regardless of the presence of an APS) who developed CPSP had experienced a higher intensity of acute pain in the first 24 hours and at discharge compared to patients, who did not suffer from CPSP. The difference in mean NRS score in the first 24 hours was in each hospital 3.5 and 3.9, respectively. Intensity of acute pain was proven as a significant risk factor for CPSP.

We tried intentionally to exclude one risk factor of CPSP - pain at the site of surgery prior to operation. This approach helped us to focus on acute pain intensity after operation and its management to assess its significance on CPSP incidence. This approach resulted in relatively low number of randomized patients after hip or knee replacement, as many of them experienced pain for longer than 3 months before the surgery.

In conclusion, acute pain intensity after operation predicted the CPSP incidence in both hospitals and acute pain intensity was a risk factor of CPSP. APS decreases the intensity of experienced acute pain after surgery. We were not able to detect a significant effect of APS on incidence of CPSP. However, data from both hospitals showed a trend toward higher incidence of CPSP in the hospital without established APS. The study is also valuable for further research to determination the minimal number of patients needed to prove a possible APS role in reduction of CPSP incidence. 
746-751

\section{Appendix 1 - Patient questionnaire}

\section{START HERE}

How to measure pain? Choose the number, which expresses the pain you have experienced, on the scale 0 to 10.0 means no pain, 10 is the worst pain you can imagine.

No pain

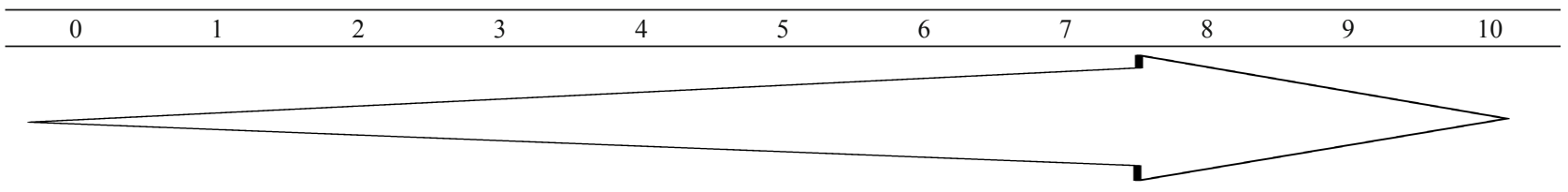

\section{Part A:}

1. Did you have any pain lasting longer than 3 months at the site of surgery BEFORE the operation?

Yes -1

No -0

If yes, we thank you for your participation in our study, you do not have to fill any of the following questions.

\section{Part B:}

2. Do you remember how intensive was your pain at the site of surgery in the first 24 hours after your operation?

Yes - 1

No -0

If yes, mark off the number, which express your pain experience in the first 24 hours after surgery.

\begin{tabular}{llllllllll}
\hline 0 & 1 & 2 & 3 & 4 & 5 & 6 & 7 & 8 & 9 \\
\hline
\end{tabular}

3. Do you remember how intensive was your pain at the site of surgery at the time of discharge from the hospital?

Yes -1

No -0

If yes, mark off the number, which expresses your pain experience at the time of discharge from the hospital.

\begin{tabular}{lllllllllll}
\hline 0 & 1 & 2 & 3 & 4 & 5 & 6 & 7 & 8 & 9 & 10 \\
\hline
\end{tabular}

4. Did you have AFTER your operation any postoperative complications at the site of surgery lasting longer than month? (wound infection, hernia in the scar etc.?)

Yes -1

No -0

If yes, describe the complication here:

5. How long AFTER the operation did you have any pain at the site of the surgery?

I do not remember

Less than 1 month

$-0$

$1-2$ months

$-1$

3 months or longer

$-2$

$-3$

I have pain till today

$-4$

\section{Part C:}

This part is concerning pain, which was lasting 3 months and longer after surgery:

6. How often did you experience pain?

Less than 1 time a week

Every week, but not every day - 1

Every day, but not a whole day (there were pain free periods during the day) $\quad-2$

Every day and whole day

7. What was the WORST intensity of this pain (regardless of how often you have experienced pain)?

\begin{tabular}{lllllllllll}
\hline 0 & 1 & 2 & 3 & 4 & 5 & 6 & 7 & 8 & 9 & 10 \\
\hline
\end{tabular}

8. What was an AVERAGE intensity of this pain in the days you have experienced pain?

\begin{tabular}{lllllllllll}
\hline 0 & 1 & 2 & 3 & 4 & 5 & 6 & 7 & 8 & 9 & 10 \\
\hline
\end{tabular}




\section{References}

1. Kehlet H, Jensen TS, Woolf CJ. Persistent postsurgical pain: risk factors and prevention. The Lancet 2006; 367 (9522): 1618-1625. doi: 10.1016/S0140-6736(06)68700-X.

2. Macrae WA. Chronic post-surgical pain: 10 years on. Br J Anaesth 2008; 101 (1): 77-86. doi: 10.1093/bja/aen099.

3. Simanski CJ, Althaus A, Hoederath S et al. Incidence of chronic postsurgical pain (CPSP) after general surgery. Pain Med 2014; 15 (7): 1222-1229. doi: 10.1111/pme.12434.

4. Perkins FM, Kehlet H. Chronic Pain as an Outcome of Surgery A Review of Predictive Factors. Anesthesiology 2000; 93: 1123-1133.

5. Bruce J, Krukowski ZH. Quality of life and chronic pain four years after gastrointestinal surgery. Dis Colon Rectum 2006; 48 (9): 1362-1370. doi: 10.1007/s10350-006-0575-5.

6. Poleshuck EL, Katz J, Andrus CH, Hogan LA, Jung BF, Kulick DI, Dworkin RH. Risk factors for chronic pain following breast cancer surgery: a prospective study. J Pain 2006; 7: 626-634. doi: 10.1016/j. jpain.2006.02.007.

7. Poobalan AS, Bruce J, Smith WC, King PM, Krukowski ZH, Chambers WA. A review of chronic pain after inguinal herniorrhaphy. Clin J Pain 2003; 19 (1): 48-54.

8. Montes A, Roca G, Sabate S et al. Gendolcat Study Group. Genetic and clinical factors associated with chronic postsurgical pain after hernia repair, hysterectomy, and thoracotomy: a two-year multicentre cohort study. Anesthesiology 2015; 122 (5): 1123-1141. doi:10.1097/ ALN.0000000000000611.

9. Powell R, Johnston M, Smith WC et al. Psychological risk factors for chronic post-surgical pain after inguinal hernia repair surgery: a prospective cohort study. Eur J Pain 2012; 16 (4): 600-610. doi: 10.1016/j. ejpain.2011.08.010.

10. Gerbershagen HJ, Ozgür E, Dagtekin O et al. Preoperative pain as a risk factor for chronic post-surgical pain - six month follow-up after radical prostatectomy. Eur J Pain 2009; 13 (10): 1054-1061. doi: 10.1016/j. ejpain.2008.11.020.

11. Gerbershagen HJ, Dagtekin $O$, Rothe $T$ et al. Risk factors for acute and chronic postoperative pain in patients with benign and malignant renal disease after nephrectomy. Eur J Pain 2009; 13 (8): 853-860. doi: 10.1016/j.ejpain.2008.10.001.

12. Wylde V, Hewlett S, Learmonth ID, Dieppe P. Persistent pain after joint replacement: prevalence, sensory qualities, and postoperative determinants. Pain 2011; 152 (3): 566-572. doi:10.1016/j.pain.2010.11.023.

13. Nikolajsen L, Brandsborg B, Lucht U, Jensen TS, Kehlet H. Chronic pain following total hip arthroplasty: a nationwide questionnaire study. Acta Anaesthesiol Scand 2006; 50: 495-500. doi: 10.1111/j.1399_ 6576.2006.00976.x.
14. Brandsborg B, Nikolajsen L, Hansen CT, Kehlet H, Jensen TS. Risk factors for chronic pain after hysterectomy: a nationwide questionnaire and database study. Anesthesiology 2007; 106 (5): 1003-1012. doi: 10.1097/01.anes.0000265161.39932.e8.

15. Althaus A, Hinrichs-Rocker A, Chapman R et al. Development of a risk index for the prediction of chronic postsurgical pain. Eur J Pain 2012; 16 (6): 901-910. doi: 10.1002/j.1532-2149.2011.00090.x.

16. Chan MT, Wan AC, Gin T, Leslie K, Myles PS. Chronic postsurgical pain after nitrous oxide anesthesia. Pain 2011; 152 (11): 2514-2520. doi: 10.1016/j.pain.2011.07.015.

17. Werner MU, Søholm L, Rotbøll-Nielsen P, Kehlet H. Does an acute pain service improve postoperative outcome? Anesth Analg 2002; 95: 1361-1372.

18. Sartain JB, Barry JJ. The impact of an acute pain service on postoperative pain management. Anaesth Intens Care 1999; 27 (4): 375-380.

19. Bardiau FM, Braeckman MM, Seidel L, Boogaerts JG. Effectiveness of an acute pain service inception in a general hospital. J Clin Anes 1999; 11 (7): 583-589.

20. Bardiau FM, Taviaux NF, Albert A, Boogaerts JG, Stadler M. An intervention study to enhance postoperative pain management. Anesth Analg 2003; 96 (1): 179-185.

21. Macrae WA, Davies HTO. Chronic postsurgical pain. In: Crombie IK, Linton S, Croft P, Von Korff M, LeResche L (Eds). Epidemiology of pain. Seattle: IASP Press; 1999, 125-142.

22. Merskey H, Bogduk N. Classification of Chronic Pain. Descriptions of Chronic Pain Syndromes and Definitions of Pain Terms. Seattle: IASP Press, 1994.

23. Kehlet H, Macrae WA, Stubhaug A. Persistent postoperative pain pathogenic mechanisms and preventive strategies. In: Mogil JS (Ed). Pain 2010. An Updated Review: Refresher Course Syllabus. Seattle: IASP Press, $2010 ; 3-12$.

24. Treede RD, Rief W, Barke A et al. A classification of chronic pain for ICD-11. Pain 2015; 156 (6): 1003-1007.

25. Wu CL, Cohen SR, Richman JM et al. Efficacy of postoperative patient-controlled and continuous infusion epidural analgesia versus intravenous patient-controlled analgesia with opioids: a metaanalysis. Anesthesiology 2015; 103 (5): 1079-1088.

26. Vavro M, Ziakova E, Gazdikova K, Farkasova D. Does standard post-operative rehabilitation have its place after knee replacement? Bratisl Med J 2016; 117 (10): 605-608.

27. Usichenko TI, Rottenbacher I, Kohlmann $\mathbf{T}$ et al. Implementation of the quality management system improves postoperative pain treatment: a prospective pre-/post-interventional questionnaire study. Br J Anaesth 2013; 110 (1): 87-95. 